International Journal of Medical Sciences

ISSN 1449-1907 www.medsci.org 2005 2(3):91-92

(C2005 Ivyspring International Publisher. All rights reserved

Editorial

\title{
Birth Defects Are Preventable
}

\author{
Andrew E. Czeizel
}

Foundation for the Community Control of Hereditary Diseases, Budapest, Hungary

Corresponding address: Andrew E. Czeizel Foundation for the Community Control of Hereditary Diseases, 1148 Budapest, Bolgárkerék utca 3. Hungary

Received: 2005.05.01; Accepted: 2005.05.25; Published: 2005.07.01

\section{Editorial}

Birth defects - or by according to the World Health Organization's (WHO) term: congenital anomalies - are structural, functional and/or biochemical-molecular defects present at birth whether detected at that time or not (Figure 1). Among different categories of birth defects, congenital abnormalities, i.e. structural-morphological defects represent the largest one.

Congenital abnormalities can be divided into three groups:

1. Lethal if the defects (such as anencephaly or hypoplastic left heart syndrome) cause stillbirth (late fetal death) or infant death or pregnancies are terminated after the prenatal diagnosis of fetal defects in more than $50 \%$ of cases.

2. Severe if the defects (such as cleft lip or congenital pyloric stenosis) without medical intervention cause handicap or death.

3. Mild if defects (such as congenital dislocation of the hip or undescended testis) require medical intervention but life expectancy is good.

Lethal and severe defects together constitute major congenital abnormalities.

Minor anomalies or morphological variants (such as epicanthal folds, ocular hypotelorism, preauricular tags and pits, low-set ears, simian crease, clino- and camptodactyly, partial syndactyly between toes 2 and 3, hydrocele, umbilical hernia, sacral dimple, etc) without serious medical or cosmetic consequences are excluded from the category of congenital abnormalities.

In general we cannot measure the incidence of congenital abnormalities due to the prenatal loss of fetuses such as blighted ova, miscarriages and ectopic pregnancies. Thus we used the term birth (live- and stillbirths) prevalence in the past. However, recently the different methods of prenatal diagnoses have been used widely for the detection of fetal defects and pregnancies are frequently terminated if the fetus is severely affected. Thus, the rate of defects is calculated for informative offspring including (i) live born infants, (ii) stillborn fetuses, and (iii) prenatal diagnosed and terminated affected fetuses and the term total (birth and fetal) prevalence of congenital abnormalities is used. Of course, the total prevalence of congenital abnormalities depends on the spectrum of congenital abnormalities evaluated, the period of study (only at birth or in early neonatal period or prenatal or the whole infant period are included), the completeness of ascertainment, the diagnostic skill of experts, demographic and genetic characteristics of the study population, etc. In Hungary the total prevalence of congenital abnormalities was 66.83 per 1000 informative offspring in the 1980s and within this, the total rate of major congenital abnormalities was 27.01 per 1000 informative offspring [1,2].

The causes of congenital abnormalities can be classified into three main groups:

1. Genetic which includes chromosomal aberrations (e.g. Down syndrome) and Mendelian single-gene defects (e.g. achondroplasia or Holt-Oram syndrome). The proportion of genetic origin is estimated about $25 \%$ of total congenital abnormalities. Mainly two conditions may contribute to a higher total prevalence of congenital abnormalities with genetic origin: (i) women giving birth after 35 years of age and (ii) high rate of consanguineous marriages.

2. Environmental which includes infectious diseases (e.g. rubella), maternal diseases (e.g. diabetes mellitus or diseases with high fever), teratogenic drugs, alcohol, smoking and environmental pollutants. The proportion of environmental origin may be about $15 \%$ of total congenital abnormalities.

3. Complex (multifactorial) origin caused by geneenvironmental interaction when the so-called polygenic liability (predisposition) is triggered by environmental 'risk' factors. Most common congenital abnormalities (such as isolated neural-tube defects, orofacial clefts, cardiovascular malformations, congenital pyloric stenosis, congenital dislocation of the hip, undescended testis, hypospadias, etc) belong to this etiological group. The proportion of complex origin is estimated about $60 \%$ of total congenital abnormalities, if congenital abnormalities with unknown origin are also included in this group.

Congenital abnormalities have two main medical characteristics: (i) defect conditions with a limited chance for complete recovery and (ii) the earliest (fetal-birth) onset. Thus, there is only one optimal medical solution and it is the prevention.

Prevention approaches are often classified into three levels:

1. Primary prevention: avoiding the cause(s) of congenital abnormalities, e.g. rubella vaccination or periconceptional folic acid/multivitamin supplementation. Some topics will be discussed in this issue. In Hungary 26.6 \% of congenital abnormalities can be primarily prevented mainly due to periconceptional folic acid/multivitamin supplementation.

2. Secondary prevention: early detection followed by effective early treatment, e.g. neonatal orthopedic screening is very effective for the early detection and treatment of deformities such as congenital dislocation of the hip based on Ortolani click and treated with different conservative methods (e.g. Pavlik pillow). In addition, 
patent ductus arteriosus and undescended testis can be corrected by drugs immediately after birth. In Hungary $25.2 \%$ of congenital abnormalities were prevented by these methods. Previously the selective abortion, i.e. termination of pregnancy after the prenatal diagnosis of severe fetal defects was also named as secondary prevention. Recently the $\mathrm{WHO}$ and other international bodies have excluded this approach from the term "prevention". In Hungary about $20 \%$ of major congenital abnormalities ( $8.7 \%$ in the total group) were terminated after the prenatal diagnosis of defects.

3. Tertiary prevention: complete recovery of congenital abnormalities by early surgical intervention without residual defects or minimal after effects. In Hungary early surgical intervention has resulted in a complete recovery in some types of congenital cardiovascular malformations (e.g. ventricular and atrial septal defects, rest of patent ductus arteriosus, etc), congenital pyloric stenosis, undescended testis, etc. Figure

Figure 1. Classification of Congenital Anomalies
Tertiary prevention helped us to achieve a complete recovery in $33.5 \%$ of cases with congenital abnormalities.

Thus, there are two main conclusions: at present the major part of congenital abnormalities (85.3\%) are preventable; however, different congenital abnormalities do not represent a single pathological entity and therefore there is no single strategy for their prevention.

\section{Conflict of interest}

The author has declared that no conflict of interest exists.

\section{References}

1. Czeizel AE, Intődy Z, Modell B. What proportion of congenital abnormalities can be prevented? Brit Med J 1996; 306: 499-503.

2. Czeizel AE. Prevention of developmental abnormalities with particular emphasis of primary prevention. Tsitologija i Genetika. 2002; 36: 56-71.

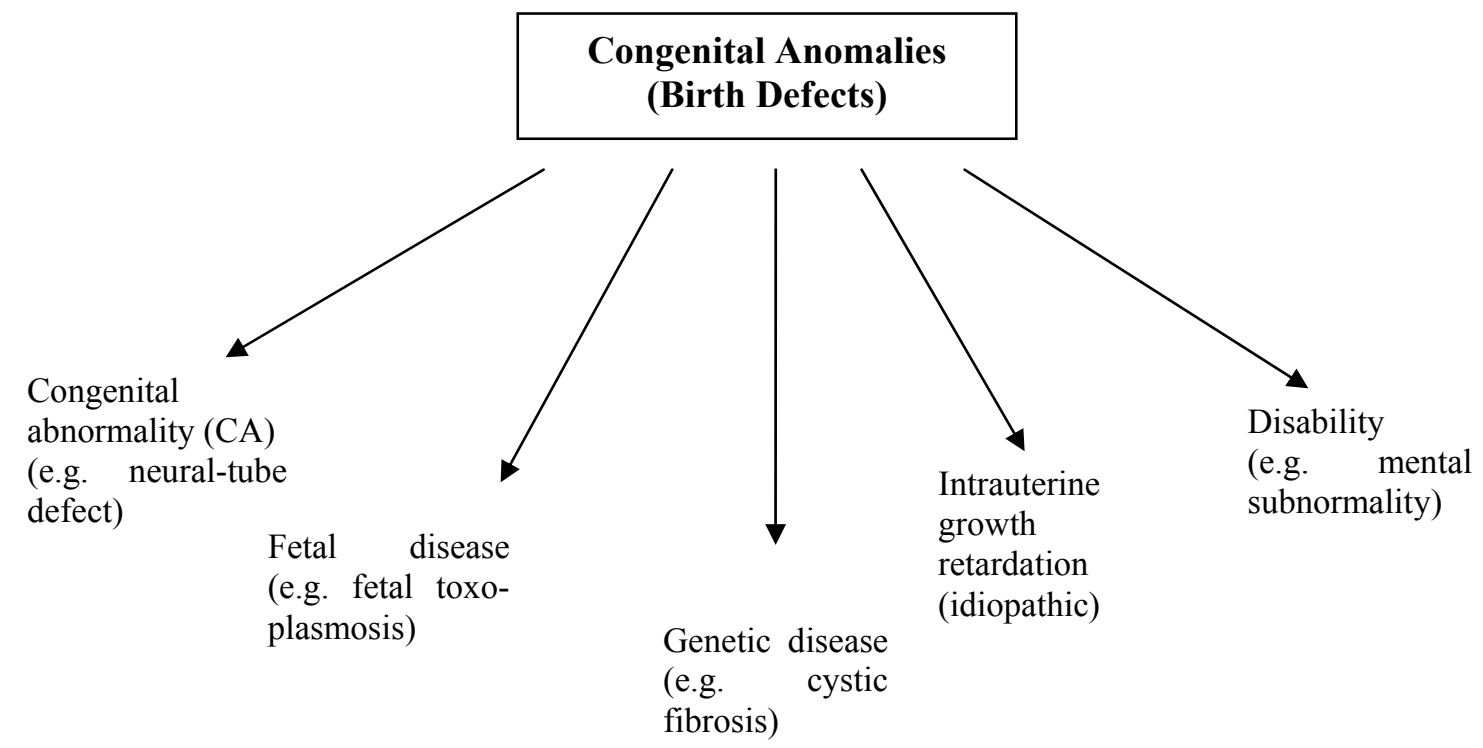

